\title{
Consumption of processed foods among children under two years of age: Foods' pattern analysis
}

Antonia Francisca Cavassim ${ }^{1}$, Cesar Augusto Taconeli ${ }^{2}$, Suely Teresinha Schmidt ${ }^{3}$, Priscilla Antunes Tsupal ${ }^{4}$ and Claudia Choma Bettega Almeida ${ }^{5 *}$

${ }^{1}$ Nutrition course academic at the Federal University of Paraná, Brazil

${ }^{2}$ Department of Statistics at the Federal University of Parana, Brazil

${ }^{3}$ Graduate Program in Food Security and Nutrition of the Federal University of Paraná, Brazil

${ }^{4}$ Department of Nutrition at the State University of the Midwest, USA

${ }^{5}$ Nutrition Course and the Graduate Program in Food Security and Nutrition of the Federal University of Paraná, Brazil

\begin{abstract}
Objective: To evaluate the consumption of processed foods and their association with socioeconomic, demographic and environmental characteristics.

Design: Cross-sectional study.
\end{abstract}

Setting: Through home interviews a pre-coded questionnaire was applied, containing data relating to food consumption and socioeconomic, demographic and environmental characteristics. Subjects: Children $(n=376)$ between six months and two years old assisted by the Family Health Program in Guarapuava, Paraná Brazil. Results: Of the 15 industrialized foods eaten more often, 8 were correlated together: artificial juice powder, soda, candy, lollipop, potato chips, margarine, refined sugar and bologna. It was found that this group of food is consumed, on average, 10 days per month. The factors that were significantly associated with increased consumption of these foods were: maternal age under 25 years, maternal education less than eight years, more than 4 people in the household, presence of other children in the household and household income per capita between 0.5 and 1 minimum wage.

Conclusions: It is evident that the early introduction of processed foods among young children is influenced by socio-economic, demographic and environmental factors.

\section{Introduction}

The first years of a child's life are characterized by rapid growth and development of psycho-motor and neurological skills. During this period, adequate food intake, capable of meeting the nutritional needs, ensures the child reaches all its biological potential. Breast milk should be the only source of nutrients for infants up to six months. From that period, the introduction of new foods in a child's diet should complement the qualities and functions of human milk by providing adequate amounts of nutrients and energy [1-4]. In addition to ensuring the additional supply of energy and nutrients, supplementary feeding gives children the development of eating habits. Through new flavors, aromas, colors and textures, the child establishes their food preferences, that impact dietary habits and practices, as well as health and nutrition throughout life [5-8].

Complementary food nutritional adequacy is essential in preventing morbidity and mortality among children represented by respiratory and gastrointestinal infections, nutritional deficiencies, malnutrition and overweight [9]. The appropriate complementary feeding should contain foods rich in energy and micro-nutrients, without contamination. According to the Brazilian guidelines on healthy eating for children under two years, consumption of sugar, coffee, canned, fried foods, soft drinks, candies, and treats should be avoided. Children tend to give preference to food the way they are presented initially, so it is recommended that foods be minimally processed and contain sugar and sodium only in its natural composition. The large supply and variety of processed foods directly affects the population's food consumption, resulting in the formation of a feeding pattern in children who get used to eating high-calorie foods, high in fats, simple sodium and sugars, devoid of essential nutrients such as vitamins, minerals and fiber. These poor eating habits formed in childhood may reflect the emergence of chronic diseases such as obesity, diabetes, cardiovascular disease and hypertension in adulthood $[2,3,6,10,11]$.

Surveys conducted in Brazil show the early introduction of fluids and food in the first year of life $[9,11,12]$, reflecting on a dietary pattern characterized by inadequate food and poor quality [13]. In particular, the consumption of processed foods, among Brazilian children, is high. Among children under one year of age, the most commonly consumed processed foods are soft drinks, coffee, biscuits and snacks. Among children 6-59 months, there is a high frequency of eating biscuits, sweets, soft drinks and snacks. Processed foods are often offered to children as a way to supplement breast milk or even the replacement of breastfeeding, highlighting the development of unhealthy eating habits from childhood [9,11-13].

Knowing the food profile of children under two years allows the

Correspondence to: Claudia Choma Bettega Almeida. 632, Lothario Meissner Street, Botanical Gardens, Curitiba, PR. +55 41 3360-4012, Brazil; E-mail: clauchoma@gmail.com

Keywords: food consumption, processed foods, infant nutrition, food pattern

Received: May 22, 2016; Accepted: June 13, 2016; Published: June 16, 2016 
subsidization of public policies to ensure food and nutrition security of this population. Thus, this study aimed to evaluate the consumption of processed foods and their association in relation to socioeconomic, demographic and environmental characteristics of children between six months and two years old assisted by the Family Health Program in Guarapuava, Paraná - Brazil.

\section{Methods}

This study is part of a larger project entitled "Promotion of breastfeeding and complementary feeding: A randomized intervention study". It is an analytical observational study in cross-sectional manner conducted in 25 health centers in the urban area of Guarapuava, district of south-central region of the Parana state, Brazil.

For the sample selection the number of children assisted by the Family Health Program in 25 health centers in the urban area of the municipality was considered. The following parameters for the sample design were considered: prevalence of the phenomenon under investigation equal to 0.5 (because prevalence of the phenomenon in the population was unknown), sampling error of 5 percentage points more or less and confidence level of $95 \%$, reaching a number of 332 children. After, it was estimated the effect of the 1.2 design reaching up to 399 children. It was increased by $20 \%$ in the sample in order to compensate possible losses or refusals to participate by mothers, totalled 479 children.

In total, 426 children between 0 and 23.9 months and their biological mothers linked to the Family Health Program (PSF) in force in the municipality 20 took part in the study ${ }^{(14)}$. In this study, the data presented are for children between 6 and 23.9 months, covering 376 children, representing $88.2 \%$ of the total survey sample.

Data collection was carried out at the homes of pre-selected families who received visits from community health workers. After signing the free and informed consent, mothers were interviewed by a previously trained team.

The data collection instrument was a questionnaire with 105 variables related to socioeconomic, demographic, environmental, health and food consumption. Sampling procedures and data collection are described in detail in another publication [14].

The frequency of food consumption questionnaire (FFCQ) was applied to parents and people responsible for the children and covered 139 types of food, distributed among the food groups: (a) cereals, tubers; (b) fruit and their juices; (c) vegetables and legumes; (d) meat and eggs; (e) milk and dairy products: (f) processed foods. The FFCQ contained 60 processed foods mentioned in the pilot study. The consumption frequency categories analyzed in this study were: a) every day; b) 4 to 6 times per week; c) 1 to 3 times per week; d) 2 to 3 times per month; e) 1 once a month; $f$ never or almost never. Some other variables incorporated in the survey were: age and mother's marital status, mother's education, mother's paid work, minimum wage per capita, received guidance on breastfeeding, if child receives breast milk, breastfeeding duration, receiving another type of milk during breastfeeding, number of people in the household, presence of other children in the household.

Once collected, the data was entered in duplicate form in the Software Epi Info 6.04 which subsequently were tabulated in Excel 2007 program. We conducted a first analysis of the data of food consumption frequency and found that among the 60 processed foods present in the questionnaire, 15 were consumed more frequently by children, and such foods were considered for subsequent statistical analysis.

Eating frequencies of the 15 processed products were analyzed by constructing frequency distribution tables, plots and using correlations. We used the polychoric correlation coefficient to quantify the correlations between variables and a basis for the realization of the factor analysis, because this coefficient is better suited in data analysis expressed in ordinal scale [14]. In addition, in order to jointly assess the eating frequency of the 15 most frequent food, we resorted to the use of multivariate analysis, more specifically, the factor analysis [15]. In the implementation of factor analysis the factor loads and other model parameters were estimated by the method of principal components and the determination of the number of factors was based on the percentage of the total explained variance and the method proposed by Kaiser [16]. A varimax rotation was applied in order to obtain a factor structure with simpler interpretation. Factor scores were calculated for each child considering the monthly approximate frequency of each of 15 foods their calculation, through the average frequency among those foods which have higher loads in the factor of interest.

Once calculated the scores for the factor of interest, we proceeded with the calculation of its mean and standard deviation at different levels of the other variables (socioeconomic, demographic and health). Trying to circle the fact of a higher overall frequency of consumption according to the child's age, scores adjusted for the child's age were calculated. A possible marginal relationship between eating frequency and other variables was assessed by applying the $t$ test or analysis of variance, according to the number of groups under comparison. For joint evaluation of the relationship between food frequency and other variables, a multiple linear regression model was fitted using as dependent variable the score of eating frequency. The accompanying variables to be inserted in the model were those that showed themselves significant at $10 \%$ in the tests performed in the previous step. Residual analysis was performed to investigate the assumptions of the model. All the analysis were performed using the statistical software $\mathrm{R}[17,18]$.

The study was approved by the Research Ethics Committee at the Health Center (CCS) - of the State University of Central West (UNICENTRO), Notion No ${ }^{\circ} 1760 / 2006$.

\section{Results}

In the selected sample most mothers are between 20 and 35 years of age (66.9\%), are married or have a stable relationship (83.1\%), have between 4 and 8 years of education (40.1\%), not working (71.9\%), living with a household income per capita less than 0.5 minimum wage $(80.8 \%)$. Most children are male $(54.1 \%)$, and the percentage of children under 6 months, 6-11 months, 12-17 months and greater than 18 months account for $11.8 \%, 258 \%, 33.8 \%$ and $28.6 \%$, respectively.

Figure 1 shows the frequency of consumption of the 15 most commonly consumed processed foods. The original frequencies were re-grouped in order to allow for simplified viewing and interpretation of results. Foods are ranked in decreasing order according to the number of children who consume them at least once a month. It is possible to see that industrialized yogurt, refined sugar and simple cookies are the processed foods that are mostly eaten with a minimum monthly frequency and margarine, tea, and petit suisse are the foods consumed less frequently among the 15 considered. However, the frequency of daily consumption indicates, prominently, that refined sugar is the food most consumed by the largest number of children, followed by simple cookies and artificial juice powder. At the other extreme, food consumed with less daily frequency in the group of the 


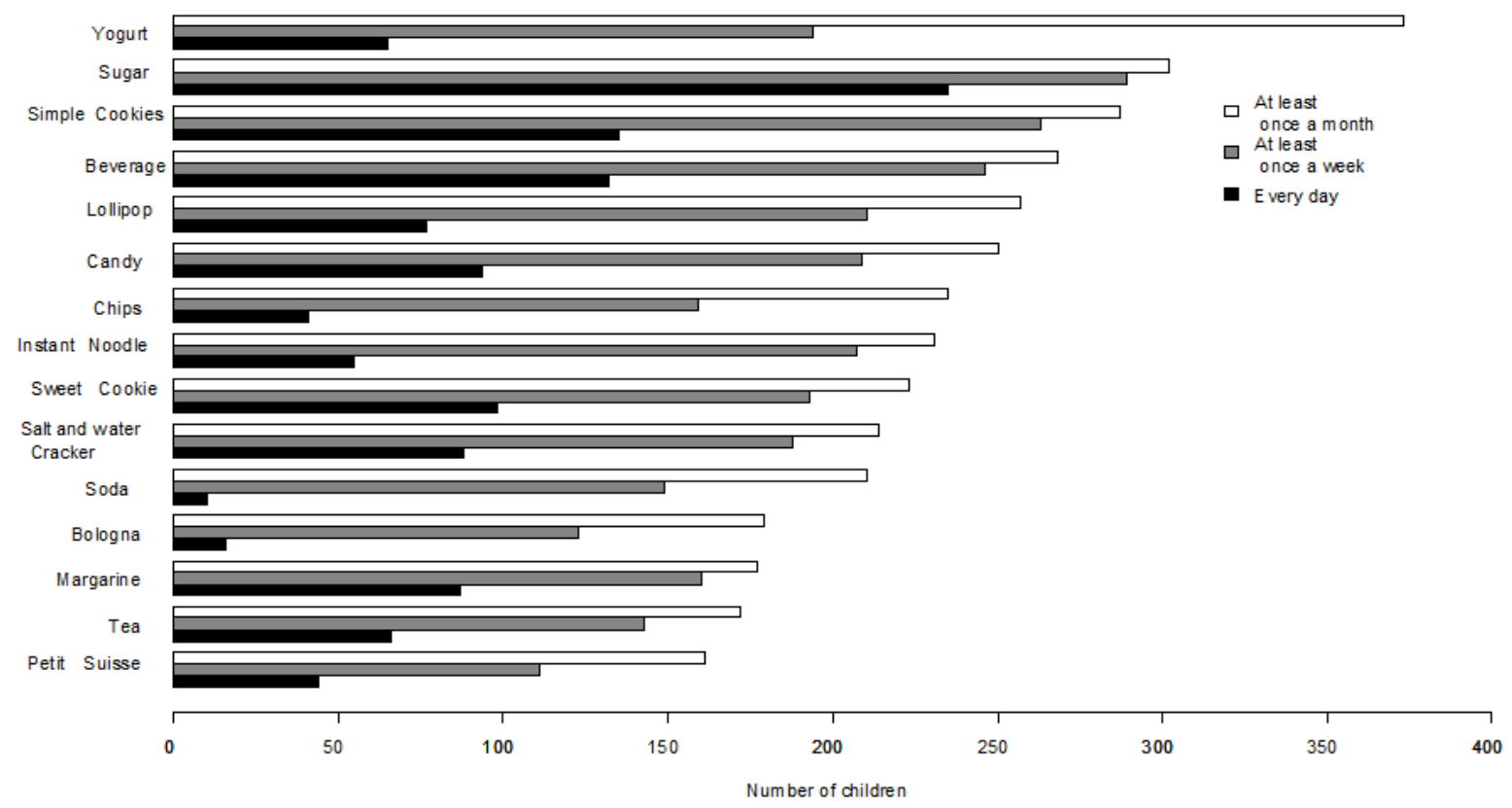

Figure 1. Frequency distribution of consumption of the 15 foods more consumed.

Table 1. Polychoric correlation matrix

\begin{tabular}{|c|c|c|c|c|c|c|c|c|c|c|c|c|c|c|c|}
\hline & Beverage & Soda & Candy & Lollipop & Chips & $\begin{array}{c}\text { Sweet } \\
\text { Cookie }\end{array}$ & $\begin{array}{l}\text { Simple } \\
\text { Cookie }\end{array}$ & $\begin{array}{l}\text { Salt and water } \\
\text { Cracker }\end{array}$ & Tea & Yogurt & $\begin{array}{c}\text { Petit } \\
\text { Suisse }\end{array}$ & $\begin{array}{l}\text { Instant } \\
\text { Noodle }\end{array}$ & $\begin{array}{c}\text { Marga } \\
\text { rine }\end{array}$ & $\begin{array}{l}\text { Refined } \\
\text { Sugar }\end{array}$ & Bologna \\
\hline Beverage & 1 & 0,33 & 0,38 & 0,36 & 0,29 & 0,23 & 0,04 & 0,04 & 0,10 & 0,08 & $-0,07$ & 0,2 & 0,26 & 0,35 & 0,31 \\
\hline Soda & 0,33 & 1 & 0,45 & 0,44 & 0,23 & 0,04 & 0,03 & 0,02 & 0,07 & 0,39 & 0,02 & 0,22 & 0,29 & 0,36 & 0,32 \\
\hline Candy & 0,38 & 0,45 & 1 & 0,79 & 0,41 & 0,05 & $-0,02$ & 0 & 0,19 & 0,14 & 0,05 & 0,20 & 0,40 & 0,44 & 0,48 \\
\hline Lollipop & 0,36 & 0,44 & 0,79 & 1 & 0,39 & 0,10 & 0,01 & 0,10 & 0,12 & 0,30 & 0,05 & 0,21 & 0,44 & 0,47 & 0,42 \\
\hline Chips & 0,29 & 0,23 & 0,41 & 0,39 & 1 & 0,02 & 0,06 & 0,13 & 0,17 & 0,18 & 0,06 & 0,24 & 0,28 & 0,30 & 0,32 \\
\hline $\begin{array}{l}\text { Sweet } \\
\text { Cookie }\end{array}$ & 0,23 & 0,04 & 0,05 & 0,10 & 0,02 & 1 & 0,72 & 0,35 & 0,06 & 0,19 & 0,11 & 0,18 & 0,16 & 0,25 & 0,17 \\
\hline Simple Cookie & 0,04 & 0,03 & $-0,02$ & 0,01 & 0,06 & 0,72 & 1 & 0,23 & 0,05 & 0,24 & 0,12 & 0,08 & $-0,03$ & 0,17 & 0 \\
\hline Salt and water Cracker & 0,04 & 0,02 & 0 & 0,10 & 0,13 & 0,35 & 0,23 & 1 & 0,14 & 0,16 & 0,08 & 0,11 & 0,20 & 0,07 & 0,23 \\
\hline Tea & 0,10 & 0,07 & 0,19 & 0,12 & 0,17 & 0,06 & 0,05 & 0,14 & 1 & 0,02 & 0,01 & 0,11 & 0,18 & 0,25 & 0,19 \\
\hline Industrialized Yogurt & 0,08 & 0,39 & 0,14 & 0,30 & 0,18 & 0,19 & 0,24 & 0,16 & 0,02 & 1 & 0,08 & 0,25 & 0,17 & 0,22 & 0,19 \\
\hline Petit Suisse & $-0,07$ & 0,02 & 0,05 & 0,05 & 0,06 & 0,11 & 0,12 & 0,08 & 0,01 & 0,08 & 1 & 0,09 & 0,02 & 0,13 & 0,13 \\
\hline Instant Noodle & 0,20 & 0,22 & 0,20 & 0,21 & 0,24 & 0,18 & 0,08 & 0,11 & 0,11 & 0,25 & 0,09 & 1 & 0,15 & 0,30 & 0,21 \\
\hline Margarine & 0,26 & 0,29 & 0,40 & 0,44 & 0,28 & 0,16 & $-0,03$ & 0,2 & 0,18 & 0,17 & 0,02 & 0,15 & 1 & 0,39 & 0,40 \\
\hline Refined Sugar & 0,35 & 0,36 & 0,44 & 0,47 & 0,30 & 0,25 & 0,17 & 0,07 & 0,25 & 0,22 & 0,13 & 0,3 & 0,39 & 1 & 0,30 \\
\hline Bologna & 0,31 & 0,32 & 0,48 & 0,42 & 0,32 & 0,17 & 0 & 0,23 & 0,19 & 0,19 & 0,13 & 0,21 & 0,40 & 0,30 & 1 \\
\hline
\end{tabular}

15 most frequently consumed foods are: soda, bologna, chips and petit suisse.

Based on the values of polychoric correlations presented in Table 1 calculated for the frequencies of consumption for each pair of food, it is observed that most of the correlation is positive, indicating the consumption of the same set. The highest correlations are found between the consumption of candy and lollipop (0.79) and simple sweet cookies and cookies like Maria (a very common cornstarch biscuit) (0.72), indicating overall, the more frequent consumption of these foods, the more frequent will be the consumption of the others as well. Much of the other correlations are between 0.3 and 0.5.

The jointly correlated foods were best expressed through the application of factor analysis, which grouped the 15 foods on a set of four factors, as shown in Table 2. Four retained factors can explain, together, $56 \%$ of data variability, very significant percentage considering that there are originally 15 variables. Furthermore, it is possible to observe that most of the commonalities are over $50 \%$, indicating that the four factors formed are able to explain quite satisfactory most of the original variables. In this process, one factor stood out as the most explanatory, contemplating, according to the associated factor loads, the following eight foods: artificial juice powder, soda, candy, lollipop, potato chips, margarine, refined sugar and bologna, which proved jointly and positively correlated. This factor is related to a poor diet, given the associated foods, expressing that such foods are offered jointly for children.

Based on the results of the factor analysis, we proceeded with the 
Table 2. Rotated factor matrix for the 15 processed foods.

\begin{tabular}{|l|c|c|c|c|c|}
\hline \multicolumn{1}{|c|}{ Food } & $\begin{array}{c}\text { Factor } \\
\mathbf{1}\end{array}$ & $\begin{array}{c}\text { Factor } \\
\mathbf{2}\end{array}$ & $\begin{array}{c}\text { Factor } \\
\mathbf{3}\end{array}$ & $\begin{array}{c}\text { Factor } \\
\mathbf{4}\end{array}$ & Communalities \\
\hline Beverages & 0.587 & & & & 0.55 \\
\hline Soda & 0.683 & & & & 0.58 \\
\hline Candy & 0.826 & & & & 0.70 \\
\hline Lollipop & 0.825 & & & & 0.68 \\
\hline Chips & 0.547 & & & & 0.36 \\
\hline Margarine & 0.578 & & & & 0.45 \\
\hline Refined Sugar & 0.639 & & & & 0.47 \\
\hline Bologna & 0.596 & & & & 0.51 \\
\hline Sweet Cookie & & 0.906 & & & 0.85 \\
\hline Simple Cookie & & 0.883 & & & 0.79 \\
\hline Salt and Water Cracker & & 0.409 & 0.511 & & 0.50 \\
\hline Tea & & & 0.646 & & 0.46 \\
\hline Yogurt & & & & 0.447 & 0.58 \\
\hline Petit-Suisse & & & & 0.771 & 0.61 \\
\hline Instant Noodle & & & & 0.304 & 0.27 \\
\hline Eigenvalues & 4.186 & 1.952 & 1.156 & 1.068 & \\
\hline \% Total variance explained & 0,261 & 0,134 & 0,084 & 0,079 & \\
\hline $\begin{array}{l}\text { Accumulated \% of the total } \\
\text { variance explained }\end{array}$ & 0,261 & 0,395 & 0,479 & 0,557 & \\
\hline
\end{tabular}

Table 3. Descriptive statistics and tests for factor scores (first factor) by the co-variables.

\begin{tabular}{|c|c|c|c|c|}
\hline Variable & Situation & $\mathbf{n}$ & Mean (sd) & p-value \\
\hline \multirow[t]{3}{*}{ Mother's years of study } & Less than 4 & 55 & $0,80(6,26)$ & \multirow[t]{3}{*}{0,038} \\
\hline & Between 4 and 8 & 144 & $0,63(5,51)$ & \\
\hline & Over 8 & 176 & $-0,78(5,24)$ & \\
\hline \multirow[t]{2}{*}{ Mother's age } & Under 25 & 191 & $0,73(5,57)$ & \multirow[t]{2}{*}{0,009} \\
\hline & 25 years or more & 185 & $-0,75(5,40)$ & \\
\hline \multirow[t]{3}{*}{ Number of people in the house } & $1-4$ & 219 & $-0,56(5,13)$ & \multirow[t]{3}{*}{0,018} \\
\hline & $5-7$ & 128 & $0,46(5,76)$ & \\
\hline & 8 or more & 29 & $2,23(6,69)$ & \\
\hline \multirow[t]{2}{*}{ Number of Children } & 1 & 223 & $0,65(5,69)$ & \multirow[t]{2}{*}{0,005} \\
\hline & 2 & 153 & $-0,95(5,17)$ & \\
\hline \multirow[t]{3}{*}{ Minimum wage per capita } & $<0,5 \mathrm{MW}$ & 287 & $0,38(5,62)$ & \multirow[t]{3}{*}{$<0,001$} \\
\hline & 0,5 to $1 \mathrm{MW}$ & 48 & $-3,20(3,70)$ & \\
\hline & $>1 \mathrm{MW}$ & 11 & $-1,55(3,60)$ & \\
\hline
\end{tabular}

consumption of score calculation of the group of 8 foods covered by the first factor for each child, allowing the discovery of the average monthly consumption (approximate) of these foods. Based on the approach discussed in the methodology there was an average frequency of consumption of the eight foods that make up the first factor, which equals 10.07 days per month. That is, we have it that approximately the mentioned foods are consumed on average 10.07 days per month.

Based on the scores adjusted by age of the child, we have, marginally, according to results presented in Table 3, the frequency of consumption of the eight industrialized foods, is related to the mother's education ( $\mathrm{p}$ $=0.038)$, the mother's age $(\mathrm{p}=0.009)$, the number of people living in the home $(p=0.018)$, to the presence of another child in the house $(\mathrm{p}=0.005)$ and per capita household income $(\mathrm{p}=<0.001)$. The same analysis showed no statistical significance between the consumption of processed foods and the marital status of the mother, the maternal work, guidance received on breastfeeding, receiving breast milk, duration of breastfeeding and the receipt of other types of milk during breastfeeding.

Following it was analyzed, at the same time, the relationship between the average monthly frequency of processed foods and the explanatory variables, identified as significant according to the Table 3, from the adjustment of a multiple linear regression model. Thus, the variables selected were: the child's age, per capita household income, mother's age and the presence of another child. Once the model was adjusted, it proceeded with the diagnosis, since it was found that one of the assumptions required for such a model (the homogeneity of the error variance) was not met. One possible cause for this is the greater spread of feeding frequencies to children from families with per capita income below 0.5 minimum wage in relation to others. This was solved by using the least squares method considered in the model adjustment, using as consideration the inverse of the variance of eating frequencies in each level of minimum wage per capita.

Based on the results of the multiple linear regression model, shown in Table 4, it is possible to see that the feeding frequency, of the group of the eight industrialized foods indicated by the first factor of factor analysis, increases as the child grows older $(p<0.001)$. Another relevant result is that the food frequency was lower for children whose families have per capita income between 0.5 and 1 minimum wage in relation to who have an income below 0.5 minimum wage $(\mathrm{p}<0.001)$. Maternal age and the presence of other children in the home were also associated with the frequency of consumption. Children whose mothers are older than 25 had a lower eating frequency compared with those who have mother under 25 years $(\mathrm{p}=0.013)$. The eating frequency of children who do not live with other (s) child (ren) in their home was also lower compared to those living with other (s) child (ren) $(\mathrm{p}=0.001)$.

\section{Discussion}

The guidelines established on healthy eating for Brazilian children recommend avoiding the consumption of processed foods, especially in the first two years of life [2,3]. The consumption of these foods, according to some studies, is influenced by factors such as age and maternal education and family income $[9,10]$. In this study a strong correlation between and statistically significant association with the child's age, educational level and maternal age, number of people residing in the home, presence of other children in the household and per capita household income. The introduction and the frequency of consumption of processed foods by children are directly related to the child's age. As age increases, the percentage of children consuming processed foods rises and increase the frequency of their consumption. Early consumption of food influences children's food preferences, that impact on dietary habits and practices, as well as health and nutrition throughout life $[3,6,19]$.

Refined sugar is consumed daily by over half of the population investigated. It is common to add sugar in the food preparations for young children, especially in liquid preparations such as milk, tea and juices, as shown in another study [10]. Excessive consumption of sugar, in addition to changing the taste of children, is associated with the emergence of various diseases such as dental caries, diabetes and obesity.

Processed foods such as simple cookies, artificial juice powder,

Table 4. Summary for the multiple linear regression fitted for the factor scores.

\begin{tabular}{|c|c|c|c|c|}
\hline Coefficient & Estimate & $\begin{array}{c}\text { Standard } \\
\text { error }\end{array}$ & Statistical test (t) & p-value \\
\hline Intercept & 2.00 & 0.96 & 2.10 & 0.036 \\
\hline Age (months) & 0.66 & 0.06 & 11.86 & $<0.001$ \\
\hline SMP (0.5-1) & -3.01 & 0.65 & -4.64 & $<0.001$ \\
\hline SMP (> 1) & -1.18 & 1.29 & -0.92 & 0.358 \\
\hline Maternal age (> 25) & -1.37 & 0.56 & -2.48 & 0.013 \\
\hline Child in the house (not) & -1.56 & 0.57 & -2.71 & 0.001 \\
\hline
\end{tabular}




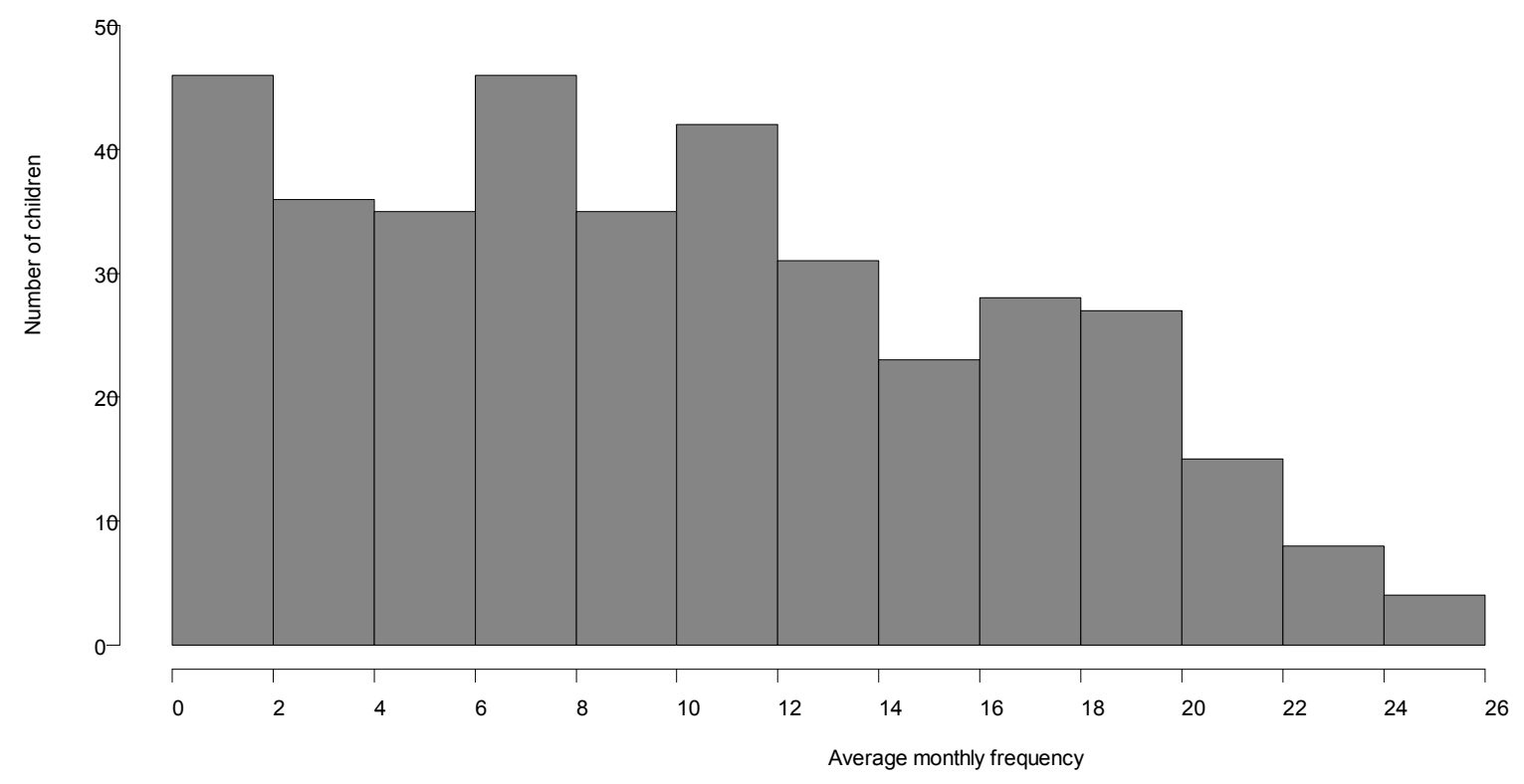

Figure 2. Distribution of the average monthly rate of 8 directly correlated food (first factor from the factor analysis).

candy and margarine are also highlighted in reference to the daily consumption. These results are equivalent to another study, which investigated the food intake of 230 children in day care centers in Brasília - DF and found that the habitual consumption profile showed up high in sugar and margarine and medium in biscuits and soda. The authors observed the early introduction of refined sugar, snack, soda, fast food, canned / processed meats and sweets/treats [20]. Similar data were obtained by The Oliveira et al. [8], which analyzed the complementary feeding of children in the first two years of life and also identified an early start of complementary food consumption and an increase of refined sugar consumption with increasing age.

As for the frequency of weekly consumption, it could ascertain a high intake of lollipop, instant noodles, industrialized yogurt and soda. These data are similar to those recorded by Caetano et al. [13], observed that the processed foods are provided to children in the very beginning, referring also to a high frequency of weekly consumption of biscuits, instant noodles, candy, artificial juice, soda and food semi-ready.

Analysis of the results showed that processed foods are strongly correlated, especially between the consumption of sweets and lollipops and between the consumption of Maria cookies (cornstarch cookie brand) and sweet biscuit. In addition, there was the discovery of the direct relationship between the consumption of refined sugar, artificial juice powder, soda, candies, lollipops, potato chips, margarine and bologna, expressing mutual supply of these foods to children, with an average monthly frequency of 10 days, indicating a pattern of unsatisfactory consumption of the nutritional standpoint since they are highly caloric foods rich in saturated fat and simple carbohydrates. These food consumption data can support themselves on the reports published by the National Household Budget Survey (2008-2009) that $61 \%$ of people have excessive consumption of sugar, $82 \%$ of people have excessive consumption of saturated fat and more than $70 \%$ of the population consume amounts in excess of the maximum tolerable intake for sodium, confirming the large percentage of inadequate nutrition of the population, which also affects the construction of dietary patterns of children in early childhood [21].

The association between dietary intake and socioeconomic, demographic and environmental factors showed that increased maternal education can have a protective effect against the consumption of processed foods, once the eating frequency is lower for children whose mother has more than 8 years of study. The research conducted by Wen et al. [22] found that maternal education had an important correlation with food patterns of young children, as mothers who had a low education level tended to feed their infant with "High sugar/ fat/protein" diet at age 12 months. Smithers et al. [23] also found that higher maternal education was associated with healthier patterns at 6 and 12 months, and reverse association were found with unhealthier patterns. The results found by Molina et al. [24] showed that low maternal education increases the child's chances of consuming a poor diet. According to the PNDS 2006 children under five years have a lower risk of exposure to obesity with increased maternal education [12]. It can be assumed that these findings indicate a lack of access to adequate information or even the slightest guidance in distinguishing what is healthier.

This study also revealed that maternal age is another factor significantly associated with the consumption of processed foods, indicating that mothers over the age of 25 years seem to offer less of these foods to their children, a result corroborated by another study [25], where the age of the parents was positively associated with vegetable intake among their children.

Studies on the consumption of processed foods do not follow a specific form of research, so do not have strictly comparative data. But household budget surveys-based studies have provided information on food consumption and have shown an increasing trend in the purchase of processed foods. Assessing the relationship between food consumption and per capita income, it was found that families with higher incomes had a lower consumption of manufactured goods in relation to families with income below half a minimum wage per capita. The data found by Jong et al. [26] shows that family income influences on the type of foods' pattern. According to the authors, children of lower incomes had high adherence to unhealthy food patterns. Dietary intake of processed products seems to decrease as the number of persons residing in the household decreases. Other relevant 
association is a relationship between the frequency of consumption and the presence of more children in the household. According to the research, the presence of another child in the same household increases intake of processed products, suggesting a higher exposure to this type of food. In this sense, others studies also found association between the presence of other children and 'confectionaries and sweetened beverages' foods' pattern $[5,19,27]$.

In conclusion, the results of this study look to the possibility of major changes in the pattern of infant feeding and indicate the direct influence of the context in which the child is placed in the consumption of processed foods. Thus, the need for intervention in the eating habits of this population through the public health services is verified, through strategies such as the Family Health Program. In addition, being able to contribute to the modification of inadequate feeding practices and encouraging the promotion of healthy eating at a young age, providing an improvement in the population's quality of life.

\section{Acknowledgments}

We thank the mothers and children of the city of Guarapuava, in the survey. The Nutrition Department of the State University of Central West (UNICENTRO). The Applied Statistics Laboratory of the Federal University of Parana for statistical support data.

\section{References}

1. Solomons NW, Vossenaar M (2013) Nutrient density in complementary feeding of infants and toddlers. Eur J Clin Nutr 67: 501-506. [Crossref]

2. Brasil, Ministério da Saúde, Secretaria de Atenção à Saúde, Departamento de Atenção Básica (2015) Saúde da criança: aleitamento materno e alimentação complementar. $2^{\circ}$ ed. - Brasília: Ministério da Saúde.

3. Brasil, Ministério da Saúde (2010) Dez passos para uma alimentação saudável: guia alimentar para crianças menores de dois anos. Brasília: Ministério da Saúde.

4. World Health Organization (2009) Infant and young child feeding: model chapter for textbooks for medical students and allied health professionals. WHO: Geneva.

5. Fisk CM, Crozier SR, Inskip HM, Godfrey KM, Cooper C, et al. (2011) Influences on the quality of young children's diets: the importance of maternal food choices. $\mathrm{Br} \mathrm{J}$ Nutr 105: 287-296. [Crossref]

6. Birch LL, Doub AE (2014) Learning to eat: birth to age 2 y. Am J Clin Nutr 99: 723S8S. [Crossref]

7. Hetherington MM, Cecil JE, Jackson DM, Schwartz C (2011) Feeding infants and young children. From guidelines to practice. Appetite 57: 791-795. [Crossref]

8. Oliveira LPM, Assis AMO, Pinheiro SMC et al. (2005). Alimentação complementar nos primeiros dois anos de vida. Rev Nutr 18: 459-469.

9. Bortolini GA, Gubert MB, Santos LM (2012) [Food consumption Brazilian children by 6 to 59 months of age]. Cad Saude Publica 28: 1759-1771. [Crossref]
10. Toloni MHA, Longo-Silva G, Goulart RMM et al. (2011) Introdução de alimentos industrializados e de alimentos de uso tradicional na dieta de crianças de creches públicas no município de São Paulo. Rev Nutr 24: 61-70.

11. Brasil, Ministério da Saúde (2009) II Pesquisa de prevalência de aleitamento materno nas capitais brasileiras e Distrito Federal. Brasília: Ministério da Saúde.

12. Brasil, Ministério da Saúde (2009) Pesquisa Nacional de Demografia e Saúde da Criança e da Mulher (PNDS - 2006). Resultados sobre amamentação e alimentação infantil. Brasília: Ministério da Saúde.

13. Caetano MC, Ortiz TT, Silva SG, Souza FI, Sarni RO (2010) Complementary feeding: inappropriate practices in infants. J Pediatr (Rio J) 86: 196-201. [Crossref]

14. Brecailo MK, Corso ACT, Almeida CCB et al. (2010) Fatores associados ao aleitamento materno exclusivo em Guarapuava, Paraná. Rev Nutr 23: 553-563.

15. Mingoti AS (2005) Análise de dados através de métodos de estatística multivariada. Editora UFMG, 295.

16. Kaiser HF (1958) The varimax criterion for analysis rotation in factor analysis. Psychometrika 23: 187-200.

17. Charnet R, Freire CAL, Charnet EMR et al. (2008) Análise de modelos de regressão linear com aplicações. Editora Unicamp, $2^{\mathrm{a}}$ edição, 368.

18. Dean CB, Nielsen JD (2007) Generalized linear mixed models: a review and some extensions. Lifetime Data Anal 13: 497-512. [Crossref]

19. Lioret S, Betoko A, Forhan A, Charles MA, Heude B, et al. (2015) Dietary pattern track from infancy to preschool age: cross-sectional and longitudinal perspectives. $J$ Nutr 145: 775-782. [Crossref]

20. Tuma RCFB, Costa THM, Schmitz BDAS (2005) Avaliação antropométrica e dietética de pré-escolares em três creches de Brasília, Distrito Federal. Rev Bras Saúde Matern Infant 5: 419-428.

21. Instituto Brasileiro de Geografia e Estatística, Ministério do Planejamento, Orçamento e Gestão (2011) Pesquisa de Orçamentos Familiares 2008-2009. Análise do Consumo Alimentar Pessoal no Brasil. Rio de Janeiro: IBGE.

22. Wen X, Kong KL, Eiden RD, Sharma NN, Xie C (2014) Sociodemographic differences and infant dietary patterns. Pediatrics 134: e1387-1398. [Crossref]

23. Smithers LG1, Brazionis L, Golley RK, Mittinty MN, Northstone K, et al. (2012) Associations between dietary patterns at 6 and 15 months of age and sociodemographic factors. Eur J Clin Nutr 66: 658-666. [Crossref]

24. Molina MCB, Lopéz PM, Faria CP et al. (2010) Preditores socioeconômicos da qualidade da alimentação de crianças. Rev Saude Publica 44: 785-792.

25. Barroso G dos S, Sichieri R, Salles-Costa R (2014) Relationship of socio-economic factors and parental eating habits with children's food intake in a population-based study in a metropolitan area of Brazil. Public Health Nutr 17: 156-161.

26. Kiefte-de Jong JC, de Vries JH, Bleeker SE, Jaddoe VW, Hofman A, et al. (2013) Socio-demographic and lifestyle determinants of 'Western-like' and 'Health conscious' dietary patterns in toddlers. Br J Nutr 109: 137-147. [Crossref]

27. Okubo H, Miyake Y, Sasaki S et al. (2014) Dietary patterns in infancy and their associations with maternal socio-economic and lifestyle factors among 759 Japanese mother-child pairs: the Osaka maternal and child health study. Matern Child Nutr 10: 213-215.

Copyright: (C2016 Cavassim AF. This is an open-access article distributed under the terms of the Creative Commons Attribution License, which permits unrestricted use, distribution, and reproduction in any medium, provided the original author and source are credited. 